\title{
Redes e cidades: reflexões acerca da cidadania
}

Adriana Pessôa da Cunha'

\section{RESUMO}

Este artigo discute as implicações redes no mundo contemporâneo sob o prisma de novos espaços de atuação. A vida social coletivizada pelas redes se organiza de outros modos. O estudo cogita o conceito de cidadania entendido numa nova dinâmica do coletivo analisando a influência das redes refletida no poder de intervenção, reflexão e interconexão de relações sociais. $\mathrm{O}$ atual conjunto dessas expressões de comportamento coletivo define os contornos do que para nós significa uma reconfiguração em diversas esferas da sociedade: dos espaços de representação; na forma como o coletivo se relaciona nas cidades; nas relações de trabalho. A cidadania trabalhada no contexto das redes e numa cultura cada vez mais mediada por relações virtuais traz um marco analítico de novo tipo, nos dando pistas que a cidadania está se reconfigurando em suas bases, abrindo caminho para percepções de um novo protagonismo social. A cidadania na era das redes trabalha sob o signo da lógica colaborativa, do compartilhamento e da auto-narrativa de representação. Essas novas experiências nos interrogam quanto ao sentido de uma cidadania ainda em formação.

PALAVRA-CHAVE: Cidadania. Tecnologias da informação. Colaborativismo. Compartilhamento.

\section{ABSTRACT}

The paper discusses the implications networks in the contemporary world of new spaces of action. Social life collectivized by networks is organized in other ways. The study consider the concept of citizenship understood in a new team dynamic by analyzing the influence of networks reflected in the power of speech, thought and interconnection of social relations. The current set of these expressions of collective behavior defines the contours of our meaning of reconfiguration in various spheres of society: the representation spaces; in the way the collective relates within the cities; labor relations. Citizenship worked in the context of networks and in a culture increasingly mediated by virtual relationships brings a new kind of analytical framework, giving us clues that citizenship is reconfiguring its bases, leading to perceptions of a new social protagonist. The citizenship in the age of networks works under the sign of collaborative logic, sharing and self-narrative of representation. These new experiences make us wonder about the meaning of a still training citizenship setting up.

KEYWORDS: Citizenship. Information and communication technologies. Collaborationism sharing.

\section{1- Introdução}

Este estudo surge a partir da necessidade de entender a descentralização dos modos de organização nas cidades, nas escolas, no lazer, no trabalho, através das mídias sociais e das redes. Segundo a percepção que defendemos o contexto das redes permite que a noção de pertencimento se transforme pela sua velocidade e capacidade de promover encontros. A reflexão sobre o tema importa em uma mudança de paradigma no que tange ao conceito de cidadania. Se antes a cidadania era alicerçada em bases sólidas, subsidiando o sujeito em fortes graus de pertencimento hoje se revela um cenário em formação, permeado de tensões, nos dando pistas que a cidadania está sendo alicerçada em outros modos de pertencer, menos hierarquizados e mais horizontalizados. Segundo a reflexão que defendemos, a cidadania que antes era definida

$1 \quad$ Mestre em Políticas Públicas pela Uerj; especialista em administração pública pela Uff; colaboradora pela Esaf; servidora pública do ministério da fazenda; advogada pela Unirio; Rio de Janeiro, Brasil. 
como algo colocado para fora do sujeito agora é constituída em novos modos de organização possibilitado pela virtualidade das redes.

A partir dos estudos desenvolvidos na dissertação de mestrado (PPFH/UERJ) realizado no ano de 2016 (CUNHA, 2016) observou-se que estes laços já não se encontram alicerçados numa determinação verticalizada de modos de organização sociais. Este contexto, afinado com os referenciais teóricos sobre o tema, foi o ponto inicial da pesquisa cuja análise será discutida neste artigo.

Em um primeiro momento conclui-se que estas novas temporalidades geradas pelo universo organizado/desorganizado das redes coloca as relações sociais, em seus distintos modos de organização com os sujeitos, como nas relações de trabalho, lazer, na escola, na relação com as cidades, modos de interação diferenciados. Estes instrumentos permitem que modos de organização, não tão verticalizados, carreguem à criação de novos espaços como poder de intervenção, reflexão e interconexão. Esta determinação das redes desloca o eixo de pertencimento que é quebrado de cima para baixo conduzindo novas representatividades e territorialização em edifícios ainda não habitáveis, atravessado de porosidades e conceitos indeterminados. O modelo de cidade, tradicionalmente hierarquizado e estratificado, já não atende ao cenário complexo e em constante transformação dos dias de hoje. Neste cenário, as relações ficam mais horizontais. A cidadania trabalhada no contexto das redes e numa cultura mediada por relações virtuais traz um marco analítico de novo tipo, nos dando pistas de um processo ainda em formação reconfigurando a cidadania em suas bases e abrindo caminho para percepções de um novo protagonismo social.

Com as novas tecnologias são consideradas dinâmicas do coletivo que inclui processos e padrões de organização de novo tipo, coerentes com o próprio movimento que é criado, gerador de novos sentidos e percepções. Esta maneira de pensar sobre a vida coloca o sujeito em contato direto com experiências desterritorializadas, em contraste se perde de si mesmo, pois ainda se vê centrado sob o eixo de hierarquias e status cujas temporalidades são muito diferentes. Em que medida este sujeito se organiza considerando-se temporalidades tão opostas?

Esta linguagem concebida pelas redes transforma modos identitários de pertencimento, como poder de intervenção e criação, produzindo nas práticas sociais novas formas de sentir, pensar, interagir e se relacionar. $O$ rápido desenvolvimento concebido por essas redes de comunicação ampliou a dimensão das relações e das práticas sociais, possibilitando vínculos entre pessoas e organizações cuja comunicação passa a ser estabelecida por meio de outros referenciais de tempo, lugar, espaço, imagens, sonoridades, e que parece indicar um possível e novo protagonismo social.

Nessa perspectiva, este artigo tem como objeto de pesquisa os espaços de atuação habilitado pelas redes sociais, visando analisar a influência destas redes como poder de intervenção, reflexão e interconexão de relações sociais, políticas, econômicas, comerciais e de serviços.

A hipótese que norteia a pesquisa é que o atual conjunto desses espaços define os contornos de uma reconfiguração em diversas esferas da sociedade: da política, dos espaços de representação, na forma como o coletivo se relaciona nas cidades, nas relações de trabalho, na economia compartilhada, na redefinição de estatutos, colocando a questão do coletivo em novo modo de organização.

Nesse contexto, o presente artigo é dividido em três seções mais considerações finais. Na seção 1 , apresento como as redes e mídias sociais proporcionaram o surgimento e a visibilidade de novos grupos e arranjos de representação. Através de várias vias permitem-se novos modos de trabalho, de produção de conhecimento, de lazer, de locomoção nas cidades, em específico uma questão urgente e controversa da nossa época - os desafios trazidos pelo aplicativo de transporte e os perigos que isto representa para as cidades. Também neste item é dedicada uma análise para o tema do financiamento coletivo e como isto vem se colocando enquanto visão de mundo. $O$ entendimento de uma nova concepção de sociedade implicada pelas redes requer uma assimilação a nível institucional e dos modos de organização do direito. Essas estruturas, enquanto reguladoras de sistemas sociais, são tidas como redes que precisam estar 
abertas para manterem-se vivas em relação a sua organização e funcionamento. Na seção 2 , trabalha-se sobre a questão do trabalho e sua flexibilização salarial sob o contexto da era da globalização. Pensando em termos de cidadania, podemos dizer que a globalização resultou numa fragmentação do trabalho à medida que há um deslocamento do eixo de pertencimento gerado pelas redes. A partir da concepção de um mercado de trabalho aberto e flexível, o tempo do trabalho, que antes era gerador de pertencimento, hoje é concebido de forma otimizada e flexível. Nesse passo, há uma mudança nos modos de organização do trabalho. A seção 3 trata da aplicação de novas tecnologias ao suporte material de outras áreas do conhecimento. Com o incremento de novas tecnologias outras áreas do conhecimento são consideradas passando a centrar-se mais nos fluxos pelos quais elas surgem havendo com isto uma maior produção com a otimização dos processos.

Nas considerações finais, apresentamos os resultados das análises e das observações sob o ponto de vista do referencial teórico, tendo em vista que este artigo se debruça sobre pesquisa documental na literatura da área e nas observações das redes. Este artigo, de cunho qualitativoexploratório, desenvolve uma reflexão sobre os caminhos que as tecnologias em rede e as redes sociais estão trilhando, visando refletir se nesse percurso está surgindo uma nova cidadania na era das redes, como proposto no título.

\section{2- A Questão dos Aplicativos de Serviços e a Disputa por Novos Espaços}

Vivemos hoje formas inusitadas de sociabilidade provocadas pelas redes sociais. Essas redes estão se revestindo de um grande poder e estão se configurando em formas de intervenção e criação em vários aspectos, ressignificando o indivíduo tanto no contexto de sua própria singularidade quanto em níveis mais coletivos de participação. Em todos os níveis de vida, seja política, econômica ou social, daí a imensa importância de entender essas novas expressões de comportamento coletivo e para que se propõem.

Já há algum tempo para se pagar uma conta não precisamos ir fisicamente até o banco, usa-se a rede online do banco onde será operada a transação financeira desejada. No domínio dos relacionamentos pessoais não é diferente. Para encontrar um novo amor ou simplesmente partilhar sentimentos e emoções passageiras, as redes se fazem igualmente presentes em endereços virtuais tais como: Par Perfeito, que cobra pelos serviços e faz parte do grupo Match. com, líder mundial em sites de encontros e relacionamentos, com usuários espalhados pela América Latina. Amores Possíveis, que disponibiliza a plataforma gratuitamente; o Second Love, voltado para homens e mulheres casados em busca de novas emoções. A chamada deste site é "Paquerar não é só para solteiros" onde há cobrança de assinatura para utilização dos serviços de encontros. Há também o "G encontros", um site de relacionamento gratuito voltado para encontros entre gays, lésbicas, bissexuais e simpatizantes de novidades. Esses sites amorosos permitem reunir pessoas que possuam a mesma afinidade e interesses na busca de relacionamentos, em variados formatos e estilos. Um dos aplicativos de relacionamento mais famosos do mundo chamado Tinder, que funciona com uma conta no Facebook, virou uma febre também no Brasil. Em entrevista ao Correio Braziliense Justin Mateen, co-fundador da plataforma, disse que o aplicativo é uma nova experiência da interação humana, tornando simples e eficiente o processo de conhecer uma nova pessoa. Além de cafés ou bares você pode encontrar os indivíduos no Tinder e conhecê-los bem antes de sair para um contato físico. Basta ativar a localização em que a pessoa está, dizer a preferência por homens ou mulheres e, a partir daí, começa a surgir fotos de pessoas que estejam próximas fisicamente com um raio de precisão acessado pelo sistema GPS do aplicativo. Se o usuário gostar, basta apertar no botão verde, caso contrário, no vermelho. Quando as duas pessoas pressionam o verde elas podem começar a conversar trocar ideias e, talvez, marcar um encontro. 
Se tomarmos como exemplo o campo dos serviços, para pegar um táxi bastam operar a interface de um aparelho com tecnologia móvel utilizando um dedo de uma das mãos e acessar aplicativos como Easy Taxi que, além de levar ao local de destino, são oferecidos serviços adicionais de segurança com rastreamento de passageiros e programas que permitem que o pagamento seja gerado pela conexão em rede do aparelho do motorista com o do usuário, sem o uso de dinheiro ou cartão de crédito. A Easy Taxi, fundada em abril de 2012 no Rio de Janeiro, é um aplicativo gratuito de serviço mobile que permite a conexão entre taxistas e passageiros. Tornou-se pioneira no serviço de táxi online, o aplicativo está redefinindo o cenário de táxi globalmente.

Além desses serviços, há parcerias com grandes empresas como Johnnie Walker entre outras que, utilizando as redes sociais como forma de disseminar um estilo cultural, imprimem também suas marcas ao concederem benefícios de desconto nas corridas de táxi àqueles que aderirem à campanha "HojeNãoDirijo", voltada para o público que sai no fim de semana de táxi e não quer se arriscar na direção com uso de bebidas alcoólicas. Note-se que estilos culturais e comerciais convergem através das redes agregando o valor de uma marca com a de um serviço de utilidade pública. Nesse sentido é construindo um forte apelo comercial ao unir "bebida" e "táxi".

Hoje a Easy Taxi e 99Taxis são os dois maiores aplicativos de táxis no Brasil. A 99Taxis, criada em 2012, ainda não avançou no exterior, mas disputa a liderança do mercado com a EasyTaxi. Na disputa, surge uma concorrente de peso no mercado dos aplicativos de táxis. O Uber serviço de transporte alternativo que funciona também com base em aplicativo. A entrada do Uber desencadeou vários movimentos de taxistas contra a plataforma, com manifestações em várias capitais como São Paulo, Rio de Janeiro e Brasília no sentido de que o aplicativo seja proibido. O argumento dos taxistas é que o app é ilegal na forma de concorrência desleal já que pagam diversos tributos, taxas e licenças para serem regulamentados. O Uber, por sua vez, diz oferecer uma forma diferente de transporte que ajuda na geração de renda para as pessoas e que sua proposta não é táxi, mas motoristas particulares que atendem a quem tem conta nesse aplicativo. Uber é um aplicativo de celular que conecta uma pessoa a um motorista particular. A referência descrita no site da Uber tem como propaganda na rede: "A escolha é algo maravilhoso". Do lado dos usuários, os relatos são de que os carros do Uber são mais confortáveis e melhores, comparativamente aos táxis convencionais. Os motoristas se vestem socialmente e andam com ar condicionado além de oferecerem água e balas sem cobrar a mais nas corridas. Já o Waze ligado em tempo real, é um aplicativo de navegação de trânsito baseado em uma comunidade de motoristas que compartilham informações de trânsito das vias em tempo real. Trata-se de um cenário novo em que novas formas de expressão do coletivo indagam a própria noção de tempo, de transporte, do uso desses espaços públicos dentro das cidades. A vida social coletivizada pelas redes se organiza de outros modos. Sem a mediação do Estado como regulador novas propostas de interação nas cidades e nos espaços de representação parecem romper com as tradicionais formas de convívio social. Esses aplicativos estão construindo uma fisionomia de relação em outro nível de trabalho e de relação com o outro. Esse novo tipo de relação habilitado pelas redes nos remete à importância de se estudar este padrão desorganizado e não-linear de organização social no contexto da atualidade.

Um reflexo das redes no campo da participação política pode ser sentido em campanhas de financiamento coletivo conhecido como crowdfunding com as quais as redes potencializam a divulgação de ideias em torno de interesses compartilhados, através de uma rede de influências de conhecidos diretos, sejam parentes ou amigos, e que acreditam naquele projeto e naquela ideia. Com essa rede, aberta e transparente, o crowdfunding promove projetos através de financiamentos coletivos online, em variadas áreas, tais como: cultura, saúde, cinema, meio ambiente, jornalismo, intervenção e espaços urbanos. Também em campanha eleitoral na forma de captação de recursos financeiros. Dados da pesquisa Retrato do Financiamento Coletivo no Brasil entre 2013 e 2014, realizada pela comunidade de financiamento coletivo Catarse, apontam que entre as regiões brasileiras que mais participam do financiamento coletivo estão o Sudeste, com 63\%; seguidas do 
Sul, com 20\%; Nordeste 9\%; Centro-Oeste, 7\%, e norte 1\%. Dados da pesquisa também apontam que $68 \%$ dos empreendedores entrevistados enxergam potencial de financiamento coletivo em seus negócios. $81 \%$ dos estudantes entrevistados estão interessados em empreender projetos próprios após se formarem. Catarse é uma comunidade de financiamento coletivo, fundada em 2011, disponibilizada em plataforma na internet. Dados de dezembro de 2014 informam que já passaram na comunidade 2.700 projetos dos quais $55 \%$ atingiram a meta do financiamento. Em 2014 foram 1.140 projetos finalizados com a participação de 88.500 pessoas que contribuíram com $\mathrm{R} \$ 12$ milhões.

Nas eleições presidenciais nos EUA, em 2008, Barack Obama utilizou o crowdfunding para imprimir sua imagem na campanha eleitoral. Pelas redes sociais, os eleitores além de financiarem a eleição com pequenas quantias sabiam a quem estavam apoiando, e, o que é mais interessante, quanto havia de arrecadação. Assim, a campanha presidencial conseguiu, além de dinheiro, mais um milhão de colaboradores. Percebe-se, com isso, a imensa importância de entender essa dinâmica colaborativa em rede que vai tomando relevo em conceitos como "micropatrocinador", "mobilize" e "não sou conduzido, conduzo" onde o lema "não sou conduzido, conduzo" assumiu o protagonismo da plataforma colaborativa nas redes e vão se inserindo em uma lógica de relação em que idealizar, realizar e intervir são elos de uma mesma rede de sentido e de mundo, como, por exemplo, o acompanhamento do comportamento dos políticos, do andamento de projetos e dos custos dos projetos.

Em 2012, o projeto denominado "Voto Consciente Jundiaí" foi fundado sob a perspectiva do voluntariado da cidade e que desde 2006 acompanha todas as sessões ordinárias da Câmara. O projeto foi bem-sucedido e financiado em 2014, com 183 apoios coletivos e R\$19.791 mil de arrecadação, tem como proposta difundir a participação coletiva nas eleições daquela região conseguindo levantar, na plataforma Catarse, a soma de R\$25 mil com a ajuda de 241 pessoas que acreditaram naquela iniciativa e naquela ideia. No projeto, os cidadãos, chamados de "cidadonos", apresentam ideias para melhorar a cidade e estas são apresentadas aos candidatos na época das eleições. Em seguida, esses candidatos, sabatinados publicamente sobre seus projetos, são acompanhados em sessões públicas da Câmara sendo dessa forma envolvidos para o debate. As ideias são impressas em "fichas públicas" e viram ações de políticas públicas para a cidade. Contando com a participação de escolas e da sociedade, essas ações já envolveram sete mil pessoas em oficinas de debates.

Entretanto, apesar do forte potencial dessas ferramentas de financiamento coletivo, em termos de mobilização e de construção política, a sua transposição para o terreno eleitoral padece de incentivos e é ofuscada por grande parte das instituições jurídicas e dos partidos políticos. Em maio de 2014, o Tribunal Superior Eleitoral (TSE) vetou a possibilidade de arrecadação de campanha por site de financiamento coletivo. Os ministros da Corte entenderam que essa forma de captação não é possível porque a doação em campanha eleitoral deve ser feita diretamente do eleitor ao candidato, não admitindo intermediários. Por outro lado, os partidos não querem perder parte de sua arrecadação, que muitas vezes advém de doação direta de empresas em troca de pequenas doações de eleitores. Geralmente, nessas plataformas virtuais de financiamento coletivo os patrocinadores são nominalmente identificáveis, sendo possível visualizar até o valor que cada um contribuiu, se assim desejarem. ${ }^{2}$

Muito embora o sistema legal brasileiro não admita "intermediários" advindos de espaços como

2 Gastos eleitorais, de origem privada, têm crescido num ritmo exponencial. Em 2002, os gastos declarados à Justiça Eleitoral por partidos e candidatos nas campanhas para deputado federal alcançaram $\mathrm{R} \$$ 189,6 milhões; em 2010, esse valor chegou ao montante de R\$ 908,2 milhões, um crescimento de $479 \%$ em oito anos. Na mesma direção, as campanhas presidenciais, que custaram R\$ 94 milhões, em 2002, alcançaram a cifra de R\$ 590 milhões em 2010, um crescimento de 627\% em oito anos. Dados retirados da consultoria legislativa da câmara dos deputados federais, fevereiro de 2014. Fonte: Disponível em: http://www2.camara. leg.br/documentos-e-pesquisa/publicacoes/estnottec/tema3/2014.pdf 
esses para captação de recursos de campanhas eleitorais, o atual processo de doação permitido na forma legal advém de vultosas somas oriundas de empresas ligadas a grandes grupos econômicos. A concentração de doações para campanha eleitoral tem origem em grandes setores da economia do país como indústria de alimentos, setor financeiro, empreiteiras e o setor de mineração. O montante de recursos por empreiteiras liderou o ranking de doações na campanha presidencial de 2014. Juntas, as construtoras contribuíram com quase R\$300 milhões, ou 30\% do total arrecadado.

As novas tecnologias também trouxeram impactos nos processos de trabalho, desencadeando uma série de comprometimentos que afetaram os trabalhadores, sendo por isso de grande colaboração analisar como isso está acontecendo atualmente.

CASTELLS (2013) situa esse debate no processo de transição histórica à medida que o progresso tecnológico de uma atividade para outra criaria, indubitavelmente, variações das estruturas do trabalho. Para ele essas tendências não se originam da lógica estrutural do paradigma informacional, mas são o resultado da reestruturação atual das relações capital-trabalho, com a ajuda das poderosas ferramentas oferecidas pelas novas tecnologias da informação e facilitadas por uma nova forma organizacional, a empresa em rede.

Por certo, essa crise vem acompanhada de uma redefinição nas relações de trabalho, estatutos e regulamentos legitimadores de profissões e os espaços de representação. A erosão de direitos põe em questão formas de identidade construídas a partir do mundo do trabalho, colocando na ordem do dia a própria noção de cidadania. Para CASTEL (2012) o processo de degradação dos eixos que constituíam os pilares da sociedade salarial vem pondo em xeque modos de socialização e formas de integração com base no trabalho, revertendo identidades, filiações, formas de coesão e de solidariedade.

No Brasil, os movimentos sociais como "15M", "Não vai ter copa" e "Vândalo é o Estado" fizeram uso das mídias utilizando as redes sociais através de posts, tags, vídeos e mensagens de texto para convocar o povo às ruas e juntos se tornarem protagonistas de seus embates contra o status quo.

O movimento " $15 \mathrm{M}$ " organizou um ato público para o dia 15 de maio de 2014, citado como dia internacional de lutas contra a copa, ao qual compareceram cerca de 21 mil pessoas distribuídas em sete estados do país. Essas comunidades virtuais se propõem a fazer denúncias sobre violações de direito e mal-uso de dinheiro público. No caso da copa do mundo no Rio de Janeiro a perda de popularidade desde o início dos protestos fez algumas empresas repensarem estratégias de eventos ligados ao torneio temendo a repercussão dessas manifestações.

Na chamada Primavera Árabe também houve forte influência das redes sociais na onda de protestos, que eclodiu em 2011, no qual milhares de egípcios foram protagonistas com vídeos e postagens via internet, cobrindo as mobilizações no Oriente Médio. Wael Ghonim, executivo do Google, em entrevista à rede de TV americana CNN, afirma que o movimento da Primavera Árabe começou em junho de 2010 no Facebook quando centenas de milhares de egípcios começaram a colaborar com o conteúdo na internet. O sociólogo francês Alain Touraine (2011) reconhece que é indispensável compreender esses movimentos que marcam uma profunda ruptura na vida política de inúmeros países e que surgiram principalmente graças à comunicação direta através das redes sociais como o facebook ou o twitter, não tendo sido definidos com clareza suficiente pela mídia tradicional, em particular pela televisão.

Já para Sami Ben Gharbia, co-fundador do blog Nawaat, ao se referir ao movimento da Primavera Árabe e às redes sociais disse que "essa foi a caixa de ressonância na luta nas ruas". Esses canais são usados para marcar encontros por ativistas e para disseminação de informação sobre lugares, horário dos protestos, formas de vigilância da atuação da polícia no local com fotos e vídeos, e debates com resumo sobre detidos ou eventos de violência ocorridos nos protestos. 


\section{3- O Trabalho e as Redes}

O trabalho representa vínculo de pertencimento e de integração do indivíduo à sociedade. $O$ trabalho humano e suas práticas vêm sendo transformadas ao longo do tempo por conta das inovações tecnológicas que estão introduzindo a mente humana no bojo da organização da produção e no padrão de trabalho. As novas bases do sistema produtivo estruturadas numa economia da comunicação, informação e conhecimento, alteraram o perfil das ocupações e das forças de trabalho, gerando desemprego e precarização. São alteradas formas de contratação, antes baseadas na produção em massa, fato que acarreta mudanças drásticas pelo esvaziamento de determinadas funções. Novas formas de contratação como o trabalho por tarefa recoloca a questão do emprego na ordem do dia, como modo de organização dentro da estrutura conceitual das redes.

Outra formulação acerca do paradigma do informacionalismo é o que tende a considerar uma supremacia do setor de serviços e os tidos "intangíveis" em detrimento do setor da indústria. $\mathrm{O}$ setor produtivo de serviços vem compreendendo um segmento de desenvolvimento cada vez maior na economia e na geração de renda e emprego ${ }^{3}$. Pode-se entender dessa reflexão que a aplicação de conteúdos de tecnologia da informação ao suporte material de setores da economia se traduz na aplicação variável de tecnologias como o uso de softwares, aplicativos, dispositivos de nanotecnologias, redes de sensores, geolocalização, biotecnologias, aplicada em diversos segmentos da economia.

A introdução das tecnologias da informação trouxe um novo modelo de relações entre produção, trabalho, consumo e mão-de-obra. Em decorrência, os parâmetros do processo produtivo introduziram uma nova divisão do trabalho sob o paradigma de uma sociedade informacional baseada na integração entre máquinas e equipamentos em computadores na organização da produção/trabalho.

Capra (2001) entende que essa nova economia se estrutura não somente em torno de fluxos de informação, mas também em fluxos de poder e riqueza que correm pelas redes financeiras globais. Esse mecanismo de ação depende em grande medida das mais avançadas tecnologias de informação e comunicação formadas e moldadas fundamentalmente por máquinas. Para ele a enorme carga de trabalho dos executivos atuais é mais uma das consequências diretas do conflito entre o tempo biológico e o tempo dos computadores. O trabalho está cada vez mais computadorizado e à medida que a tecnologia dos computadores progride, essas máquinas trabalham cada vez rápido, e assim economizam cada vez mais tempo. A questão de saber o que fazer com o tempo que sobra se torna uma questão de valor. O tempo pode ser distribuído entre os indivíduos que compõem a organização - criando-se um tempo para que eles reflitam, organizem-se, façam contatos e reúnamse para conversas informais - ou pode ser subtraído da organização e transformado em mais lucro para os acionistas e executivos de primeiríssimo escalão - obrigando-se as pessoas a trabalhar mais e, assim, aumentar a produtividade da empresa. Infelizmente, a maior parte das empresas da nossa tão admirada era da informação optou pela segunda alternativa.

Conforme indica Guy Standing (2013) a sociedade do mercado global está fazendo com que a nossa percepção de tempo se insira por meio de outros formatos:

3 Dados da Pesquisa Anual de Serviços (PAS) do IBGE - Instituto Brasileiro de Engenharia e Estatística, no Brasil a participação no PIB do setor produtor de serviços segundo as contas nacionais situou-se em 58,3\% em 1999, respondendo por 57,2\% da absorção de mão-de-obra na economia. A PAS constitui fonte de dados setoriais do comportamento do mercado formal sob a ótica da oferta de serviços. Seus resultados referemse às empresas atuantes em atividades de serviços mercantis não-financeiros, abrangendo as atividades de alojamento e alimentação, transportes e serviços auxiliares dos transportes, correio e telecomunicações, informática, serviços imobiliários e de aluguel de bens, serviços prestados principalmente às empresas e outras atividades de serviços (serviços auxiliares financeiros, representantes comerciais e agentes do comércio, serviços auxiliares da agricultura, serviços recreativos, culturais e desportivos e serviços pessoais). 
Historicamente, cada sistema de produção tinha como estrutura norteadora um conceito específico de tempo. Na sociedade agrária, a tarefa e o trabalho eram adaptados ao ritmo das estações e das condições climáticas. Qualquer ideia de um dia de trabalho normal de 10 ou 8 horas teria sido absurda. Não havia sentido em tentar arar a terra ou fazer a colheita sob uma chuva torrencial. O tempo podia não esperar pelo homem, mas o homem respeitava seus ritmos e variações espasmódicas. (STANDING, 2013, p.178).

Com os avanços cada vez mais intensos em telecomunicações o aparecimento de verdadeiras unidades de escritório, automatizadas em redes, intensificou a concepção de empresa em unidades descentralizadas de blocos. A organização do trabalho sob esse enfoque revolucionou a ideia de trabalho desenvolvido dentro das cidades em escritórios fisicamente localizados. Formando uma rede interativa com capacidade de se comunicar em tempo real, processar a informação, se comunicar e até tomar decisões de forma compartilhada essas unidades descentralizadas favorecem a ideia de deixar a empresa cada vez mais flexível, com contratos de trabalho também mais flexíveis.

Segundo a Associação dos Centros de Negócio e Escritórios Virtuais (ANCNEV) o setor cresce, em média, 30\% ao ano. Já são mais de 990 salas e cerca de 79 mil usuários em todo o Brasil. A pesquisa aponta que além da economia nos custos a falta de mobilidade das grandes cidades é um dos motivos para o crescimento do setor, já situado em cerca de $40 \%$ em escritórios virtuais, estando concentrado em sua maior parte na região Sudeste como é o caso do Rio de Janeiro. Isso trouxe dispensa de grande parte de trabalhadores, redução de custos de mão-de-obra e aumento do capital.

\section{4- O Uso de Tecnologias em Outras Áreas de Conhecimento}

A aplicação de novas tecnologias de comunicação ao suporte material de outras áreas do conhecimento têm aprofundado vários estudos dentro uma compreensão sistêmica da sociedade. Conectando corpos, máquinas e equipamentos cada vez mais parecidos com as pessoas. Um exemplo que ficou muito conhecido foi a utilização do exoesqueleto na copa do mundo realizada no Brasil, em 2014. Com a utilização de uma interface cérebro-máquina, através de estímulos captados por eletrodos que devolve a informação ao paciente, foi possível fazer o retorno da informação através do cérebro, em interação com um computador ${ }^{4}$.

Inúmeras são as transformações ocorridas em decorrência dos atuais sistemas de informação. $O$ padrão em redes alterou diversos campos da atividade econômica. Castells (2013) pontua que a introdução de tecnologias da informação ao suporte material de áreas da atividade humana como software para computadores, produção de vídeos, projeto de microeletrônica, agropecuária com base em biotecnologia e muitos outros processos cruciais característicos das economias avançadas juntam, irremediavelmente, seu conteúdo de informação ao suporte material do produto, impossibilitando a distinção dos limites entre "bens" e "serviços" (CASTELLS, 2013, p. 269). Com isto percebe-se uma otimização da própria produção.

A rápida capacidade de se comunicar mediada por essas tecnologias (smartphones, aparelhos que integram telefonia, internet, televisão, câmeras de alta resolução, gravadores de áudio e geolocalização, redes de computadores, redes sociais, perfis individuais, blogs e fotoblogs), seja

$4 \quad$ Um computador central decodifica os sinais recebidos e devolvem ao paciente, por meio do exoesqueleto, a informação de movimento e permitindo a possibilidade de movimento a quem já a perdeu (p.ex. paraplégicos). 
na forma escrita, pictórica ou visual, acarreta a possibilidade de uma penetração comunicacional e uma conectividade a nível global que transforma a comunicação em todas as suas faces, tanto culturalmente quanto socialmente.

Dados do IBGE sobre indicadores de acesso à Internet e posse de telefone móvel celular para uso pessoal, obtidos a partir das informações da Pesquisa Nacional por Amostra de Domicílios (PNAD 2011) mostram que em $2011,77,7$ milhões de pessoas de 10 anos ou mais de idade acessaram a Internet no período de referência nos últimos três meses. Este contingente equivalia a $46,5 \%$ do total da população de 10 anos ou mais de idade. Em 2009, o número de internautas foi estimado em 67,7 milhões, representando $41,6 \%$ da população-alvo. Nos anos de 2008 e 2005, estes totais foram estimados em 55,7 milhões (ou $34,7 \%$ da população-alvo) e 31,9 milhões (ou 20,9\% da população-alvo), respectivamente. De 2005 para 2011 a população de 10 anos ou mais de idade (população em idade ativa) cresceu 9,7\%, enquanto o contingente de pessoas que utilizaram a Internet aumentou 143,8\%, ou seja, em seis anos o número de internautas no País cresceu 45,8 milhões ${ }^{5}$. Esses sistemas de comunicação estão caminhando cada vez mais para a convergência tecnológica, unindo e conectando não somente pessoas, mas também dados, como tweets, mensagens, post em redes sociais, vídeos, geolocalizações, e até comportamento de clientes. No terremoto do Haiti em 2010 pesquisadores americanos perceberam antes de todo mundo a diáspora de Porto Príncipe por meio dos dados de geolocalização de 2 milhões de chips SIM de celulares, facilitando a atuação da ajuda humanitária.

Assim, um universo de fluxos globais de informação, signos e linguagens fizeram com que determinados regimes de identificação do quotidiano como o tempo da escola, do trabalho e o tempo doméstico se desterritorializem, criando nova relação com o tempo e com o espaço. Diferente das formas de organização da vida em unidades de blocos de tempo sequencialmente previstos e organizados as redes sugerem modos de organização baseado num padrão não linear.

Percebe-se, assim, que a organização da vida, anteriormente regulada e disposta em blocos de hora como hora de trabalhar, hora de estudar, hora de encontrar, está sendo construída em uma relação tempo-espaço totalmente diferente. Segundo Standing (2013),

O funcionamento da sociedade e da produção era baseado em blocos de tempo, junto com ideias de locais de trabalho e de moradia fixos. Durante a vida, as pessoas frequentavam a escola por um curto período, depois passavam a maior parte da vida trabalhando e depois, se tivessem sorte, tinham um curto período de aposentadoria. Durante seus "anos de trabalho", acordavam de manhã, trabalhavam por 10 ou 12 horas, ou pelo tempo que estivesse estabelecido em seus contratos vagamente definidos, e depois iam para "casa". Havia "feriados", mas eles encolheram durante a industrialização e foram substituídos gradualmente por curtos blocos de férias. Embora os padrões variassem por classe e gênero, o importante é que o tempo era dividido em blocos. A separação de "local de trabalho" e "local de moradia" fazia sentido (STANDING, 2013, p.179)

$5 \quad$ Este estudo foi desenvolvido com base nos dados da Pesquisa Nacional por Amostra de Domicílios - PNAD realizada em 2005, 2008, 2009 e 2011. Foi perguntado para todos os moradores com 10 anos ou mais de idade, com base na data da entrevista, se tinham acessado a Internet nos últimos três meses em qualquer local, lembrando que as entrevistas da PNAD são realizadas sempre no último trimestre de cada ano. http:// ftp.ibge.gov.br/Acesso_a_internet_e_posse_celular/2011/PNAD_Inter_2011.pdf. 
Novos comportamentos também se fazem presentes no setor da educação em relação ao tempo. Dados do Censo da Educação Superior de 2013, divulgados pelo Ministério da Educação, apontam que no segmento da EAD - educação à distância - no período entre 2011-2012 as matrículas avançaram $12,2 \%$ nos cursos à distância e $3,1 \%$ nos presenciais. Com esse crescimento a modalidade a distância já representa mais de $15 \%$ do total de matrículas em graduação.

Segundo dados do Censo da Educação Superior divulgados pelo Instituto Nacional de Estudos e Pesquisas Educacionais Anísio Teixeira - INEP um terço do crescimento de matrículas no ensino superior entre 2003 e 2013 foi registrado nos cursos de educação à distância, majoritariamente na rede privada. O número saltou de 49.911 em 2003 para a cifra surpreendente de 1.153 .572 matrículas em 2013.

Zygmunt Bauman (1999) identifica que com o advento das redes certos significados de sentido se tornaram "extraterritoriais". Isto tem um reflexo direto no contexto das cidades. Segundo o autor, planejado o espaço moderno tinha que ser rígido, sólido, permanente e inegociável. Concreto e aço seriam a sua carne, a malha de ferrovias e rodovias os seus vasos sanguíneos. A totalidade social devia ser uma hierarquia de localidades cada vez maiores e mais inclusivas, com a autoridade supra-local do Estado empoleirada no topo, supervisionando o todo e ao mesmo tempo protegida da vigilância cotidiana. Sobre esse espaço planejado, territorial-urbanísticoarquitetônico, impôs-se um terceiro espaço cibernético do mundo humano com o advento da rede mundial de informática. Ela emancipa certos seres humanos das restrições territoriais e torna extraterritoriais certos significados geradores de comunidade - ao mesmo tempo em que desnuda o território, no qual outras pessoas continuam sendo confinadas, do seu significado e da sua capacidade de doar identidade (BAUMAN, 1999, p. 24-25).

O contexto da globalização remete assim a um padrão de sociabilidade baseado no individualismo em perspectiva com uma nova noção de espaço e tempo. Os desconfortos da existência localizada compõem-se do fato de que, com os espaços públicos removidos para além do alcance da vida localizada, as localidades estão perdendo a capacidade de gerar e negociar sentidos (BAUMAN, 1999 , p. 8). Com o quotidiano das pessoas atravessado por sistemas de comunicação interativos os espaços se interpenetram a cada instante e as comunicações nas cidades são redefinidas pela difusão dessa lógica da mobilidade.

O surgimento dessas tecnologias no contexto das escolas também traz à tona um aspecto importante a ser observado. A escola idealizada na sociedade industrial, pautada pelos ideais e compromissos da sociedade moderna, era configurada para fazer frente a métodos e atividades educativas com o propósito de responder ao projeto histórico da sociedade moderna e do Estadonação. Como resultado, a escola era tida como verdadeira máquina de ensinar, com divisão por lugares fixos e individuais, a disciplina rígida com horários pré-determinados e a vigilância constante de um professor em sala-de-aula que impunha sua hierarquia e poder de obediência aos alunos. A escola foi uma das instituições de confinamento, assim como a fábrica, os hospitais e o seio do lar doméstico por onde se engendraram diversos moldes, corpos dóceis e úteis formatados para funcionar e pôr em funcionamento as engrenagens do capitalismo industrial: "À última pancada do relógio, um aluno baterá o sino, e, ao primeiro toque, todos os alunos se porão de joelhos, com os braços cruzados e os olhos baixos" (FOUCAULT, 2013, p. 145).

\section{5- Considerações Finais}

Chegamos ao final deste artigo e vamos apresentar agora nossas conclusões, como pistas para discussões futuras. Vimos que o padrão das redes sugere a identificação de nós, células, teias, sobreposições que formam um tecido autogerador comum que afastado do estado de equilíbrio cria tensões em pontos críticos da sociedade. Concluímos que a noção de rede sob o enfoque 
social e no contexto das tecnologias informacionais ainda se situa em campo de estudo com pouca referência teórico-conceitual, aspectos da própria dinâmica dos sistemas abertos onde a vida se organiza constantemente na direção de modos de regulação e caos. Nessa perspectiva, a problemática levantada neste artigo apontou que espaços de atuação habilitados pelas redes sociais traz novo significado enquanto modos de organização do social. Pode-se notar através destas ferramentas informacionais que o significado é essencialmente sentido no campo social, em novos formatos de intervenção, reflexão e interconexão de relações sociais, políticas, econômicas, comerciais, relacionamentos e serviços. Nesse sentido, a pesquisa aponta que o padrão em rede traz uma horizontalidade aos modos de pertencimento re-significando a noção de cidadania.

Desta forma, a cidadania não se produz mais em um modo verticalmente identitário. Essa ausência de sentido é percebida em diversos campos do social. Há, portanto, uma mudança de paradigma. O trabalho fixo, em horas pré-definidas era tido como um modo de pertencimento. Quem não se estruturasse desse modo de pertencer era considerado um não cidadão. Cidadão era aquele que se disponibilizava, que se submetia a esta forma de organização do trabalho. A pesquisa aponta que essa compreensão já não se insere no terreno das garantias, atravessado pelas novas tecnologias estes modos de pertencer agora se organizam de outras formas. Isso cria uma tensão como identidade social já que, para se manter vivo, a própria dinâmica do coletivo rearruma o fluxo visando estabelecer minimamente o lugar que ocupa na teia.

Outra questão que foi observada na pesquisa é que vivemos hoje a desfiliação das relações quase em todos os campos sociais: nas cidades, no trabalho, na política, nas relações familiares, na escola, na carreira profissional, nos relacionamentos. Até no campo do relacionamento amoroso vivemse hoje novas configurações de parceria. Nos aplicativos de encontro, por exemplo, os modos de encontrar estão implicados em referenciais estranhos aos próprios interlocutores já que não há uma história prévia que vai dizer sobre aquela pessoa que ali se disponibiliza ao diálogo. A construção de histórias advém desses encontros, que se organizam como fenômenos vivos e espontâneos, atuando as redes como mediadoras das relações na direção da singularidade. As novas tecnologias criam, portanto, novas temporalidades e modos de encontros.

A partir da pesquisa realizada, pode-se observar que novas bases de pertencer estão sendo gestadas, demolidos determinados aspectos de pertencimento e acolhimento que tradicionalmente uniam os indivíduos. O trabalho sob a forma de emprego estável permitiu a filiação ao exercício da cidadania e ao regime de proteção advindo dessa relação, ou seja, a forma de integração via trabalho e ao status de cidadania. As proteções foram sendo vinculadas às posições ocupacionais de trabalho por onde o eixo estruturante de cidadania se consolidou como forte componente de integração. Parecenos que hoje a solução é completamente inversa. A desfiliação de nossos dias é uma realidade que se produz em diversas esferas das relações sociais. Esse mecanismo é tão forte e potente que as pessoas que não têm trabalho se sentem duplamente desencaixadas. Sem proteção e sem trabalho buscam a própria redenção num sonho ideal de pertencimento, cada vez mais transitório e distante.

O estudo analisou que o modelo de cidadania tradicional e verticalizado parece estar se esgotando e isso não é um fenômeno que advém da atualidade de nossos dias. As transformações se deram por movimentos caóticos. Hoje temos uma nova dinâmica das cidades, de um protagonismo que ainda está se formando e pode vir a se constituir em resposta às exigências da contemporaneidade. Avista-se o surgimento de uma nova linguagem, menos convencional, uma fala que interroga, que diz e mostra, teatraliza e mente e que, de certa forma, também faz referência às exigências da contemporaneidade onde o sujeito se apresenta fragmentado e ambivalente, repleto de infinitas identidades.

Ponto importante do estudo revela que, embora a cidadania continue ainda referência como modo de pertencer enquanto matriz institucional, agora ela quer ser outra e pertencer de modos novos tendo as redes como referencial para o incremento desta via comunicacional. Parece-nos que essa cidadania quer se mostrar de forma horizontal, para dar conta das questões do dia-a-dia e 
das diversidades. Nos espaços des-hierarquizados atravessados pelas redes a linguagem formada pelos próprios atores, com suas críticas, sugestões e escolhas, torna a dinâmica da sociedade mais plural e viva a partir de um senso comum de problematização. Há movimentos nas redes que integram as exigências da contemporaneidade como novos espaços de representação. Esses movimentos deixam claro que as redes sociais se tornaram um fenômeno de modos de organização da contemporaneidade. Como protagonistas reais dos acontecimentos os sujeitos são dotados de significado. A linguagem das redes os tornam criadores, produtores e atores de suas próprias histórias auto narrativas e, paralelamente, transitam nesse mundo dotado de profunda ambivalência e solidão em busca de abrigos possíveis e estáveis. Isto é percebido na diversidade de aplicativos que se colocam frente ao social atravessado por essas novas tecnologias.

Assim, é preciso pensar esses novos territórios existenciais por meio de uma reflexão do que é cidadania hoje. Cabe a pergunta: cidadão é só local ou ele é global? Vimos que na era das redes as funções e os processos se organizam cada vez mais em torno do contexto rede. Portanto, a escola também passa por um processo de crise e traz à cena a falência desse modelo tradicional de pertencimento. De um lado muros, salas de aula e carteiras enfileiradas; de outro as redes em espaços des-hierarquizados. De um lado telas em tempo real com recursos audiovisual, livros e cadernos digitais; de outros quadros-negros e giz. De um lado paredes amareladas; de outro o espaço global, livre e desinteressado das redes. A escola conectada com aparelhos ligados à internet e telefones celulares cada vez mais modernos e coloridos se contrapõe à rigidez e opacidade do já amarelado instituto chamado escola. Parece-nos que os alunos de hoje são outros, incentivados pela lógica do mundo das redes, mas vigiados com câmeras dispostas em cada canto do pátio. As redes convidam alunos e professores para novas dinâmicas da contemporaneidade.

O panorama desenvolvido no presente artigo aponta que temos uma enorme crise institucional e existencial na medida em que o indivíduo se apresenta livre em suas escolhas, mas preso ao nível dos padrões estabelecidos de outrora. Precisamos refletir sobre o que a cidadania representa hoje, convidada a todo instante pelas redes como elemento criador e fonte crítica de poder, mas ainda organizada em bases sólidas que alienam o sujeito através da produção de uma cidadania ainda atravessada por referências hierarquizadas e estabilizadoras não dando conta deste sujeito que se organiza cada vez mais em torno das redes. 


\section{Referências Bibliográficas}

BAUMAN, Zygmunt. Comunidade: a busca por segurança no mundo atual. Rio de Janeiro: J. Zahar, 2003.

Globalização: as consequências humanas. Rio de Janeiro: J. Zahar, 1999.

CASTELLS, Manuel. A galáxia da internet: reflexões sobre a internet, os negócios e a sociedade. Trad. Maria Luiza X. de A. Borges. Rio de Janeiro: J. Zahar, 2003. Tradução de: The internet galaxy: reflections on the internet, business and society.

CASTELLS, Manuel. Redes de indignação e esperança: movimentos sociais na era da internet. Rio de Janeiro: J. Zahar, 2013.

DELEUZE, Gilles. Post-scriptum sobre as sociedades de controle. In: Conversações: 1972-1990. Tradução de Peter Pál Pelbart. São Paulo: 34, 1992. p. 219-226. (Coleção TRANS).

DELEUZE, Gilles; GUATTARI, Félix. Mil platôs: capitalismo e esquizofrenia 2. São Paulo: 34, 1995. v. 2. (Coleção TRANS).

FOUCAULT, Michel. Em defesa da sociedade: curso no Collège de France (1975-1976). 2. ed. São Paulo: Martins Fontes, 2010.

Vigiar e punir: história da violência nas prisões. 41. ed. Petrópolis: Vozes, 2013.

HABERMAS, Jürgen. O Estado-nação europeu frente aos desafios da globalização: o passado e o futuro da soberania e da cidadania. Novos Estudos, n. 43, p. 87-101, nov. 1995.

A inclusão do outro: estudos de teoria política. São Paulo: Loyola, 1996.

SIBILIA, Paula. A construção de si como um personagem real: autenticidade intimista e declínio da ficção na cultura contemporânea. Revista ECO Pós, Rio de Janeiro, v. 15, n. 3, p. 22-46, 2012.

2012.

Redes ou paredes: a escola em tempos de dispersão. Rio de Janeiro: Contraponto,

STANDING, Guy. O precariado: a nova classe perigosa. Belo Horizonte: Autêntica, 2013. (Invenções democráticas, v. 4).

TOURAINE, Alain. Crítica da modernidade. 10. ed. Petrópolis: Vozes, 2012.

2011.

Um novo paradigma: para compreender o mundo de hoje. 4. ed. Petrópolis: Vozes, 